\title{
TENURE STATUS, HOUSING CONDITIONS AND RESIDENTIAL SATISFACTION OF ADOLESCENTS
}

\author{
Anna Matel \\ University of Bialystok \\ e-mail:a.matel@uwb.edu.pl
}

\begin{abstract}
The paper aims to investigate factors connected with the residential satisfaction of the adolescents and to compare them with the factors influencing residential satisfaction among adults. The primary research was conducted in secondary schools in the Bialystok Functional Area. The data was analyzed using descriptive statistics and a multinomial logistic regression model. The results show that living standards are a crucial issue in residential satisfaction. Living in an owner-occupied dwelling and having one's own room reduced the likelihood of being dissatisfied with housing.
\end{abstract}

Key words: residential satisfaction, housing satisfaction, tenure status, housing conditions.

JEL Classification: R30, D01.

Citation: Matel, A. (2020). Tenure status, housing conditions and residential satisfaction of adolescents. Real Estate Management and Valuation, 28(4), 24-32.

DOI: https://doi.org/10.1515/remav-2020-0029

\section{Introduction}

Residential satisfaction is a frequently studied research subject. This issue is discussed and examined especially in the context of well-being (Clapham, et al., 2018; Hu \& Ye, 2019). The topic is rarely undertaken in CEE countries. Most of the research is connected with American, British, Eastern European or Asian economies. According to the housing adjustment theory, households judge their housing conditions by housing norms that are agreed upon and culturally derived (Morris \& Winter, 1975). This means that the level of residential satisfaction is strongly conditioned by the cultural and institutional context, as well as by the average standard of living and social inequalities in the economy. As a result, it seems particularly interesting to explore this issue in Poland.

Another reason why the studied appears interesting is that the vast majority of research from the field of residential satisfaction are conducted among adults. In this context, young people seem to be an interesting research group. Firstly, such research can help us to understand the relation between housing conditions and the well-being of adolescents. According to current literature (e.g. Coley, et al., 2013; Clair, 2019), housing, especially its quality and stability, has a prominent impact on children's development. As a result, it is important to investigate which housing conditions are the most important for their housing satisfaction. Parents usually tend to provide good living conditions for their children, so it appears important to know which housing conditions influence their children's satisfaction the most. Finding out whether the residential satisfaction of an adolescent is influenced by the same factors as adults' takes on particular importantance. Another reason why this seems to be a significant subject is the potential impact of children's satisfaction on their parents' housing decisions, though it remains unknown how strong such an influence is.

Residential satisfaction is defined in different ways in the literature, which results in various methodological approaches to its measurement. Canter and Rees (1982) defined it as "a reflection of the degree to which the inhabitants feel their housing is helping them reach their goals". A similar approach - referring to individual aspirations - was proposed by Fernández-Portero et al. (2017). They defined residential satisfaction as individual residential conditions (home, district and community) in 
relation to the needs, expectations and objectives of the residents. Residential satisfaction understood in this way - is the difference between the household's actual and desired residential situation (Mohit, et al., 2010). It contains a certain emotional component, as it is a subjective measure of the occupants feeling (Francescato, 1979).

Literature shows that there are two prevailing approaches to analyzing satisfaction with residential conditions. Dekker et al. (2011) looked into the matter from two perspectives: satisfaction with a dwelling and satisfaction with the estate. The first approach focuses on the characteristics of the dwelling itself (if its large enough or if it has enough amenities), while the other refers to a broader range of residential conditions, such as the neighbours, the physical state of the area or the location relative to the city centre.

Most of the studies investigate the factors affecting residential satisfaction among adults. There is a tendency to explore particular demographic groups: the poor or middle-income families (Aulia \& Ismail, 2013; Mohit, et al., 2010), people in certain age groups, e.g. the elderly (Fernández-Portero, et al., 2017; Vera-Toscano \& Ateca-Amestoy, 2008), people having specified tenure status (Deurloo, et al., 1994; Diaz-Serrano, 2009; Elsinga \& Hoekstra 2005), e.g. tenants (Ibem \& Amole, 2013; Jiboye, 2009; Kaitilla, 1993; Mohit \& Azim, 2012) or residents in particular types of housing (Paris-Deidre, Kangari Roozbeh 2005). Research exploring residential satisfaction among young people can also be found (Milić \& Zhou, 2018). It usually concerns people who have gained independence and are starting their own families. Students' residential satisfaction is yet another subject of research (Ibem \& Amole, 2013; Jansen, 2014; Khozaei, et al., 2010; Moore, et al., 2019; Najib, et al., 2011). However, when the literature is analyzed, one may observe a lack of such studies carried out among adolescents. In this paper, the author aims to investigate factors influencing adolescents' residential satisfaction and to compare them with factors influencing the residential satisfaction among adults. To accomplish this goal, the results of the primary research conducted in secondary schools in the Bialystok Functional Area were analyzed using descriptive statistics and the multinomial regression model.

\section{Literature review}

Two basic ways of assessing residential satisfaction are applied. The first one is based on asking people directly about their feelings. In this way, respondents assess their satisfaction on the scale proposed in the questionnaire (Amérigo \& Aragonés, 1997). Other researchers consider residential satisfaction as a predictor of behaviour and investigate this phenomenon by observing or asking about the intention to stay at or move out of the current place of residence (Weidemann \& Anderson, 1985). In the present study, the first approach was implemented.

Basing on literature, it could be noticed that there are three basic groups of factors influencing residential satisfaction: (1) the physical conditions of the dwelling (2) the neighbourhood and (3) individual and household socio-demographic characteristics (Balestra \& Sultan, 2013). Housing affordability could also be considered to be a factor differentiating the residential satisfaction of the households (Balestra \& Sultan, 2013, p. 8).

\section{(1) the physical conditions of the dwelling}

One of the most important factors influencing residential satisfaction is tenure status (Dekker, et al., 2011; Elsinga \& Hoekstra, 2005; Lu, 1999). The relation between general satisfaction among the European communities and living in an owner-occupied flat was explored by Elsinga and Hoekstra (2005). They found out that, in European countries - with the exception of Austria - homeowners were, only the whole, more satisfied than the tenants. They explain this phenomenon by indicating that homeowners usually feel more secure in their houses, have a sense of freedom and, to some extent, gain financial benefits (imputed rents). Deurloo et al. (1994) noted that homeowners usually have higher incomes than tenants. As a result, they also have greater opportunities to satisfy their needs. Diaz-Serrano (2009), while observing the same households for a given period of time, indicated that renters experience a significant increase in housing satisfaction after becoming homeowners.

In many studies the connection between residential satisfaction and the physical appearance of the dwelling was analyzed (Dekker, et al., 2011; Lu, 1999). Housing quality is not a single variable. To assess it, a number of indicators are used, including the type of building, the size of a dwelling and the presence of facilities (Elsinga \& Hoekstra, 2005). In reagrds to building type, detached and semidetached houses as well as multi-family housing is distinguished. According to Diaz-Serrano (2009), 
those individuals in European countries who live in detached or semi-detached properties reported higher levels of housing satisfaction than ones living in apartments or flats. A subsequent feature influencing residential satisfaction is the living area. Households usually seek such a size of a dwelling that can meet their requirements (Baker, 2008). However, generally speaking, the bigger the dwelling, the more satisfied the residents are. Respondents living in smaller apartments revealed lower satisfaction (Dekker, et al., 2011; Milić \& Zhou, 2018). Another measure to assess the living area is the number of rooms. According to Balestra and Sultan (2013), satisfaction decreases along with a lower number of rooms per person in a dwelling.

A feature associated with the size of the flat is the perceived lack of privacy. As it was observed by Adriaanse (2007), this has a negative influence on residential satisfaction. Ibem and Amole (2013) noticed that, in general, young people who live independently (without their parents) generally declared higher residential satisfaction. Aspirations to live on one's own are often observed among young people (Cirman, 2006).

Another factor of residential satisfaction is the existence of so-called structural problems in the dwelling, also referred to as the housing deprivation symptoms, which are defined as insufficient basic functioning of the dwelling. This applies to conditions seen as an absolute necessity in order to ensure a decent quality life and live with dignity (Guio, et al., 2009). Among deprivation symptoms are: the presence of rot in window frames, doors and floors, damp and leaks, and the lack of an indoor flushing toilet (Mandic \& Cirman, 2012). Milić and Zhou (2018) analyzed the relations between residential satisfaction and such problems as: old electrical installations, moisture and mold, the lack of daylight, insects and insufficient heating. They found that the more frequently problems occurred, the less satisfied the respondents were (similar: Balestra \& Sultan, 2013).

Paris Deidre and Kangari Roozbeh (2005) indicated that, among the tenants of multifamily affordable housing in Atlanta, a crucial role in shaping residential satisfaction was played by property management, including: applied tenant selection policies, enforcing residential rules and property management staff quickly responding to the residents' concerns.

\section{(2) the neighborhood}

The second group of factors influencing residential satisfaction is neighborhood and localization. Grigolon et al. (2014) analyzed the influence of the degree of urbanization on residential satisfaction. They indicated that lower satisfaction is caused by congestion and noise from the outside. As a result, people often aspire to move to less dense places. Localization is also connected with environmental factors, such as the quality of air and water (Balestra \& Sultan, 2013).

The availability of amenities, facilities and services in proximity of a dwelling is yet another factor of residential satisfaction (Waziri, et al., 2014). The factors studied in this context include: local employment opportunities, the efficiency of public transport and access to recreational areas (Balestra \& Sultan, 2013). The distance from the workplace or shopping sites as well as the quality of public services have been additionally studied (Grzeskowiak, et al., 2003).

When exploring the influence of the neighborhood on residential satisfaction, Amérigo and Aragonés (1997) found that, among housewives in Madrid, not only physical conditions, but also the so-called social environment (i.e. the relations in the neighbourhood) was deemed important. Similarly, Jansen (2014) pointed at the influence of mutual help and respect among neighbours. Meanwhile, Parkes et al. (2002) investigated social ties and social interaction.

\section{(3) Individual and household socio-demographic characteristics}

As was emphasized by Amérigo and Aragonés (1997), the residential environment (both, the physical attributes of the dwelling and its surrounding) are evaluated by individuals with regard to their personal characteristics (age, gender, the living arrangements, health status, etc.). This means that different sociodemografic profiles of inhabitants are associated with different housing needs. From the range of socio-demographic features, mainly age, having children and income are explored as the predictors of residential satisfaction. According to van Praag et al. (2003), individuals who are under the age of 35 are more likely to declare low residential satisfaction than respondents aged 35 or more. Balestra and Sultan (2013) found that, in European countries, families with two or more children were generally less satisfied with housing conditions than families with one child. Another explored factor was income, which is usually positively correlated with the residential satisfaction seeing as how a higher income enables households to fulfill their housing needs by adjusting both the physical 
conditions of the dwelling and the neighborhood to ones' needs. On the other hand, some researchers claim that wealthy people may also have higher aspirations (Balestra \& Sultan, 2013).

Factors influencing housing satisfaction may vary depending on the person's age. There are studies in literature indicating the specificity of residential satisfaction of the older people, including ones living in the residential care homes, and young people, especially students, including ones living in dormitories. Residential satisfaction of older adults (the category most often refers to people over 60) is associated with such factors as: home attributes, environmental quality, the network of neighbors, the building's amenities (Rojo Perez, et al., 2001). The set of these factors is similar to adults. According to Rojo Perez et al. (2001), residential satisfaction was higher among women and the most elderly. Rioux and Werner (2011) found the quality of local areas and access to services to be especially important. In James's (2008) research, neighborhood quality was found to be more strongly associated with residential satisfaction in older adults than in younger persons. This relation was the subject of the research undertaken by Beyer et al. (2017). They indicated that neighborhood attachment predicted positive changes in the residential satisfaction of older people. For people living in residential care homes, the set of factors is slightly different, but the quality of the neighbourhood, expressed by interactions with peer residents, remains crucial. The quality of services and care facilities also take on importance in such accommodation (Liu, et al., 2017, p. 272).

In the literature, residential satisfaction of young people is mainly analyzed in terms of students' satisfaction with living in students' housing or satisfaction with dormitories (Amole 2009). According to Amole (2009), residential satisfaction of students living in dormitories was associated with the social qualities of the dormitories, room functionality and several students' demographic characteristics. Najib et al. (2011) indicated the relation between the level of the students' satisfaction with campus housing facilities. According to (Amole 2009), an crucial factor was also whether a student had a private bedroom (similarly: Milić \& Zhou, 2018). Moore et al. (2019), on the other hand, pointed out the importance of the stage of studies, i.e. the closer to the end of studies, the lower the satisfaction declared by the students. The research also indicated the importance of property management, including the time of response to complaints.

In this context, as it was indicated by Najib et al. (2011), it should be emphasized that student housing and family housing are not the same. Thus, there still seems to be a lack of knowledge regarding factors influencing the residential satisfaction of young people with their family housing conditions. In this context the author is particularly interested in whether tenure status is also important for them, as is the case observed in adults.

\section{Data and Methods}

The conducted study sought to answer the following research question: what are the factors which affect adolescents' residential satisfaction? It also seems particularly interesting to find out how these factors differ from the residential satisfaction reported among adults.

The primary research, using the Paper and Pencil Interview method, was conducted in May of 2018, among pupils in their prenultimate year of secondary schools in the Bialystok Functional Area (BOF). There were 28 secondary schools in the area. Students were randomly chosen and next the survey was carried out in all prenultimate classes in the chosen school. $63.2 \%$ of the students declared living in cities, $34.6 \%$ of them were studying in a secondary technical school. $52.5 \%$ of the respondents were male, $85.3 \%$ declared having siblings, and $81.6 \%$ declared that they live with both parents $(18.4 \%$ reported to be living with one parent). Unfortunately, no data regarding the distribiution of variables in the general population are available. It should be noted that EU-SILC (European Union Survey on Income and Living Conditions) data are also used in the studies of residential satisfaction. Some limitations aside (lack of certain information), it would be beneficial to compare EU SILC results in the future.

In author's opinion, the best method allowing the stated research question to be answered would be an ordinal logit/probit model. Due to statistically significant test of parallel lines, a more suitable method was the multinomial regression model (more: Stanisz, 2016). The structural parameters of the models were estimated using the maximum likelihood method. The dependent variable was residential satisfaction. The declared level of satisfaction was assessed using the following scale: definitely dissatisfied, rather dissatisfied, rather satisfied, definitely satisfied. Due to the fact that most respondents declared to be very satisfied or rather satisfied with their dwelling, a group was formed 
from the people who were not satisfied with their residential situation. The variable was re-coded into three categories: very satisfied, rather satisfied and dissatisfied (similarly: Balestra \& Sultan, 2013).

Table 1

Explanatory variables - coding and differences in the level of declared residential satisfaction

\begin{tabular}{|c|c|c|}
\hline Definition, coding (number) & $\begin{array}{c}\text { arithmetic } \\
\text { mean } \\
\text { (standard } \\
\text { deviation) }\end{array}$ & $\begin{array}{c}\text { a measure } \\
\text { of } \\
\text { association } \\
\text { between } \\
\text { variables }^{\text {a }}\end{array}$ \\
\hline all respondents $(\mathrm{N}=612)$ & $2.55(0.61)$ & - \\
\hline \multicolumn{3}{|l|}{ gender: } \\
\hline $1-$ girls $(\mathrm{N}=287)$ & $2.50(0.63)$ & \\
\hline 0 - boys $(N=317)$ & $2.60(0.60)$ & 0.09 \\
\hline \multicolumn{3}{|l|}{ whether the dwelling is located: } \\
\hline 1- in the city $(\mathrm{N}=381)$ & $2.51(0.61)$ & \\
\hline 0 - in the village $(\mathrm{N}=221)$ & $2.62(0.61)$ & $0.135^{*}$ \\
\hline \multicolumn{3}{|l|}{ centre: } \\
\hline 1- living in the city center $(\mathrm{N}=86)$ & $2.47(0.66)$ & \\
\hline 0 - other $(\mathrm{N}=522)$ & $2.57(0.60)$ & 0.061 \\
\hline \multicolumn{3}{|l|}{ tenure status: } \\
\hline 1- owner - living in an owned house / flat $(\mathrm{N}=554)$ & $2.58(0.58)$ & \\
\hline 0 - tenant - living in a rented house / flat $(\mathrm{N}=54)$ & $2.26(0.78)$ & $0.187^{* *}$ \\
\hline \multicolumn{3}{|l|}{ dwelling type: } \\
\hline $\begin{array}{l}\text { 1- house (detached house, semi-detached or terraced } \\
\text { house) }(\mathrm{N}=368)\end{array}$ & $2.64(0.57)$ & \\
\hline 0 - apartment or flat $(\mathrm{N}=230)$ & $2.41(0.66)$ & $0.178^{* *}$ \\
\hline \multicolumn{3}{|c|}{$\begin{array}{l}\text { the number of rooms per person in the dwelling, } \\
\text { excluding kitchen, bathroom and corridor (in the } \\
\text { models expressed as quantitative variables): }\end{array}$} \\
\hline - less then one $(\mathrm{N}=226)$ & $2.42(0.70)$ & \\
\hline - one $(N=134)$ & $2.56(0.57)$ & \\
\hline - two or more $(\mathrm{N}=238)$ & $2.70(0.49)$ & $0.223^{* *}$ \\
\hline \multicolumn{3}{|l|}{ self-assessed standard of the dwelling: } \\
\hline 0 - poor $(\mathrm{N}=103)$ & $2.04(0.78)$ & \\
\hline 1- average or luxury $(\mathrm{N}=499)$ & $2.67(0.42)$ & $0.311^{* *}$ \\
\hline \multicolumn{3}{|c|}{$\begin{array}{l}\text { whether any of the listed housing deprivation signs are } \\
\text { present (leaky roof, no bathroom, no central heating, too } \\
\text { dark, not warm enough): }\end{array}$} \\
\hline $0-$ no $(N=561)$ & $2.59(0.59)$ & \\
\hline $1-$ yes $(\mathrm{N}=47)$ & $2.13(0.74)$ & $0.192^{* *}$ \\
\hline \multicolumn{3}{|l|}{ having own room: } \\
\hline $1-$ yes $(\mathrm{N}=492)$ & $2.64(0.53)$ & \\
\hline $0-$ no $(\mathrm{N}=116)$ & $2.19(0.77)$ & $0.325^{* *}$ \\
\hline
\end{tabular}

Source: own study.

A set of explanatory variables relating to the individual, the household and the dwelling was chosen (Table 1). Demographic variables included the gender and the index of the number of rooms per the number of household members. A higher number of variables were related to the dwelling including: the tenure status, the dwelling type, the standard of the dwelling, housing deprivation signs and having a room to oneself. There were also some variables related to the surroundings of a 
dwelling, like: urbanization and living in the city center. A total of 9 factors were analyzed, eight of which were binary variables and one was a quantitative variable.

The level of residential satisfaction differs based whether the respondent had a private room in the dwelling (the Cramer's V coefficient was 0.325). The standard of the dwelling was also an important variable. The respondents declaring a luxurious or average standard of their dwelling, on average declared residential satisfaction at the level of 2.67 , while among people living in dwellings characterized by a poor standard, the average amounted to 2.04 . This was a large difference, resulting in Cramer's V coefficient at the level of 0.311. Statistically significant but smaller differences were also observed for the following variables: the tenure status (adolescents living in owner-occupied dwellings were more satisfied with housing conditions than tenants), the dwelling type (higher satisfaction among respondents living in the houses) and the place of residence (higher satisfaction among respondents living in the village than in the city). Statistically insignificant differences were observed in terms of: gender and the number of persons in the household.

\section{Empirical results}

Multinomial logistic regression was applied to investigate the factors influencing the probability of a particular level of residential satisfaction among respondents. The model met the basic criteria of fitting to the data (model fitting test and goodness of fit test). R-square, the parameter which do not reach 1 in logistic regressin models (Hosmer \& Lemeshow, 2000), was at a high level (over 0.6). "High satisfaction" was chosen as the base category. It allowed better model fitting parameters to be obtained, because the differences in the characteristics of "satisfied at an average level" and "dissatisfied" proved to be more significant than the differences in the characteristics of respondents highly satisfied and satisfied at an average level. To control the multicollinearity, the $\phi$-coefficient was used. The two variables were assessed as highly correlated if the coefficient was higher than 0.3 (Fleiss, 1981). In such a procedure, the variable "dwelling is located in the city or in the village" was excluded (due to its relationship with the variable "the type of the dwelling", $\phi$-coefficient=0.494).

Table 2

Multinomial regression models of residential satisfaction of adolescents in the Bialystok Functional Area

\begin{tabular}{lrr}
\hline \multirow{2}{*}{ Varible } & \multicolumn{2}{c}{$\begin{array}{c}\text { Alternative (base alternative - highly } \\
\text { satisfied) }\end{array}$} \\
\cline { 2 - 3 } & dissatisfied & $\begin{array}{r}\text { satisfied at } \\
\text { average level }\end{array}$ \\
\cline { 2 - 3 } gender & 2.079 & $1.639^{* *}$ \\
\hline living in city center & 1.812 & 1.087 \\
\hline tenure status (owner) & $0.201^{* *}$ & 0.929 \\
\hline dwelling type (house) & 0.430 & 0.539 \\
\hline the number of rooms per person & $0.285^{*}$ & 0.756 \\
\hline $\begin{array}{l}\text { self-assessed standard of the dwelling (average } \\
\text { or luxurious) }\end{array}$ & $0.034^{* *}$ & $0.382^{* *}$ \\
\hline housing deprivation sign(s) in the dwelling & & $3.012^{* *}$ \\
\hline having one's own room & $0.167^{* *}$ & 0.818 \\
\hline
\end{tabular}

Model fitting test sig.= 0.000; goodness of fit sig = 0.657; pseudo R-square Nagelkerke = 0.628; pseudo Rsquare McFadden $=0.372$

* significant at the 10 per cent level; ** significant at the 5 per cent level.

Source: own study.

The likelihood of residential dissatisfaction among adolescents in comparison with their high satisfaction was conditioned by having one's own room, the self-assessed standard of the dwelling, living in deprived housing conditions, the number of rooms per person and the tenure status. Having one's own room reduced the probability of being dissatisfied with the housing conditions by over $80 \%$, while living in housing with some signs of deprivation increased dissatisfaction almost fivefold. Living in housing assessed as average or luxurious significantly reduced the probability of being 
dissatisfied with housing conditions as compared with housing assessed as poor. Moreover, living in an owned house reduced the likelihood of dissatisfaction with residential conditions. No significant effect of gender, living in the city center and building type was observed. It can be noticed, that the sets of variables differ between respondents who are highly satisfied and satisfied at average level. First of all, it was more probable for girls to present an average level of satisfaction. Boys were more likely to express high satisfaction. There was no difference between adolescents having or not having an own room. This means that having a room of one's own increases residential satisfaction only to a certain level. The same situation occurred in case of tenure status. The likelihood of being moderately satisfied in comparison with highly satisfied was approximately three times higher if there were some signs of deprivation in the dwelling. Summing up, some factors like housing deprivation and the standard of the dwelling affected residential satisfaction of respondents who were satisfied at an average level and those who were not satisfied. Other factors only influenced dissatisfaction (having one's own room, tenure status, the number of rooms per person). Ohers still increased satisfaction from a medium to high level (gender).

\section{Discussion and conclusions}

The aim of the conducted study was to identify the factors which determine residential satisfaction among adolescents. According to primary research conducted in the Bialystok Functional Area, tenure status proved to be a significant factor in residential satisfaction. This relationship was reported in a wide range of studies conducted on adults. Examples include: Dekker, et al., 2011; Elsinga \& Hoekstra, 2005; Lu, 1999, Diaz-Serrano, 2009. In the case of adolescents, this influence occured but was not as strong as usually observed among adults. It can be concluded that being a tenant increased the probability of residential dissatisfaction more than being an owner increased residential satisfaction. Another significant factor was the standard of the dwelling, which was also observed among adults (Dekker, et al., 2011; Lu, 1999). Adolescents also found it important to have their own room. This is undoubtedly related to the need for privacy, as observed by Adriaanse (2007) and Ibem, Amole (2013). The level of satisfaction with residential conditions among adolescents did not differ in regards to the distance to the city center or building type. In general, residential dissatisfaction among adolescents is determined by living in poor housing conditions and having own personal space in the dwelling. The level of residential satisfaction was conditioned by housing standard and it was observed that boys were more likely to be highly satisfied.

\section{References}

Adriaanse, C. C. M. (2007). Measuring Residential Satisfaction: A Residential Environmental Satisfaction Scale (RESS). Journal of Housing and the Built Environment, 22(3), 287-304.

Amérigo, M., \& Aragonés, J. I. (1997). A theoretical and methodological approach to the study of residential satisfaction. Journal of Environmental Psychology, 17(1), 47-57.

Amole, D. (2009). Residential satisfaction in students' housing. Journal of Environmental Psychology, 29(1), 76-85.

Aulia, D. N., \& Ismail, A. M. (2013). Residential Satisfaction of Middle Income Population: Medan city. Procedia: Social and Behavioral Sciences, 105, 674-683. https://doi.org/10.1016/j.sbspro.2013.11.070

Baker, E. (2008). Improving Outcomes of Forced Residential Relocation: The Development of an Australian Tenants' Spatial Decision Support System. Urban Studies, 45(8),1712-1728.

Balestra, C., \& Sultan, J. 2013, Home Sweet Home: The Determinants of Residential Satisfaction and Its Relation with Well-Being, OECD Statistics Working Papers, 5, https://www.oecdilibrary.org/economics/home-sweet-home-the-determinants-of-residential-satisfaction-and-itsrelation-with-well-being_5jzbcx0czc0x-en (16 July 2019).

Beyer, A., Kamin, S.T., \& Lang R. (2017). Housing in Old Age: Dynamical Interactions Between Neighborhood Attachment, Neighbor Annoyance, and Residential Satisfaction. Journal of Housing For the Elderly, 31(4), 382-393.

Canter, D., \& Rees, K. (1982). A Multivariate Model of Housing Satisfaction. Applied Psychology, 31(2), 185-207.

Cirman, A. (2006). Housing Tenure Preferences in the Post-privatisation Period: The Case of Slovenia. Housing Studies, 21(1), 113-134.

Clair, A. (2019). Housing: an Under-Explored Influence on Children's Well-Being and Becoming. Child Indicators Research, 12(2), 609-626. 
Clapham, D., Foye, Ch., \& Christian, J. (2018). The Concept of Subjective Well-being in Housing Research, Housing. Theory and Society, 35(3), 261-280.

Coley, R.L., Foye, Ch., Leventhal, T., Lynch, A.D., \& Kull M. (2013). Relations between housing characteristics and the well-being of low-income children and adolescents. Developmental psychology, 49(9), 1775-1789.

Dekker, K., de Vos, S., Musterd, S., \& van Kempen R. (2011). Residential Satisfaction in Housing Estates in European Cities: A Multi-level Research Approach. Housing Studies, 26(04), 479-499.

Deurloo, M. C., Clark, W A V., \& Dieleman, F. M. (1994). The Move to Housing Ownership in Temporal and Regional Contexts. Environment and Planning A: Economy and Space, 26(11), 16591670.

Diaz-Serrano, L. (2009). Disentangling the housing satisfaction puzzle: Does homeownership really matter? Journal of Economic Psychology, 30(5), 745-755.

Elsinga, M., \& Hoekstra, J. (2005). Homeownership and housing satisfaction. Journal of Housing and the Built Environment, 20(4), 401-424.

Fernández-Portero, C., Alarcón, D., \& Barrios Padura, A. (2017). Dwelling conditions and life satisfaction of older people through residential satisfaction. Journal of Environmental Psychology, 49, 1-7. https:// doi.org/10.1016/i.jenvp.2016.11.003

Fleiss, J. L. (1981). Statistical Methods for Rates and Proportions. John Wiley \& Sons.

Francescato, G. (1979). Residents' Satisfaction in HUD-Assisted Housing: Design and Management Factors. U.S. Department of Housing and Urban Development.

Grigolon, A., Dane, G., Rasouli, S., \& Timmermans, H. (2014). Binomial Random Parameters Logistic Regression Model of Housing Satisfaction. Procedia Environmental Sciences, 22, 280-287. https://doi.org/10.1016/j.proenv.2014.11.027

Grzeskowiak, S., Sirgy, M. J., \& Widgery R. (2003). Residents' Satisfaction with Community Services: Predictors and Outcomes. Journal of Regional Analysis and Policy, 33(2), 1-36.

Guio, A. C., Fusco, A., \& Marlier, E. 2009, A European Union Approach to Material Deprivation Using EU-SILC and Eurobarometer Data. IRISS at CEPS/INSTEAD, https://ideas.repec.org/p/irs/iriswp/2009-19.html (21 May 2019).

Hu, M., \& Ye, W. (2019). Home Ownership and Subjective Wellbeing: A Perspective from Ownership Heterogeneity. Journal of Happiness Studies, 21, 1059-1079. https://doi.org/10.1007/s10902-019$\underline{00120-y}$

Ibem, E. O., \& Amole, D. (2013). Residential Satisfaction in Public Core Housing in Abeokuta, Ogun State, Nigeria. Social Indicators Research, 113(1), 563-581.

Jansen, S. J. T. (2014). The impact of the have-want discrepancy on residential satisfaction. Journal of Environmental Psychology, 40, 26-38. https://doi.org/10.1016/j.jenvp.2014.04.006

Jiboye, A. D. (2009). Evaluating Tenants' Satisfaction with Public Housing in Lagos, Nigeria. Town Planning and Architecture, 33(4), 239-247.

Kaitilla, S. (1993). Satisfaction with Public Housing in Papua New Guinea: The Case of West Taraka Housing Scheme. Environment and Behavior, 25(3), 514-545.

Khozaei, F., Hassan, A. S., \& Khozaei, Z. (2010). Undergraduate Students' Satisfaction with Hostel and Sense of Attachment to Place: Case Study of University Sains Malaysia. American Journal of Engineering and Applied Sciences, 3(3), 516-520.

Liu, S., Ouyang, Z., Chong, A.M., \& Wang H. (2018). Neighborhood Environment, Residential Satisfaction, and Depressive Symptoms Among Older Adults in Residential Care Homes. The International Journal of Aging and Human Development, 87(3), 268-288.

Lu, M. (1999). Determinants of Residential Satisfaction : Ordered Logit vs. Regression Models, Growth and change. Journal of Urban and Regional Policy, 30(2), 264-287.

Mandic, S., \& Cirman, A. (2012). Housing Conditions and Their Structural Determinants: Comparisons within the Enlarged EU. Urban Studies, 49(4), 777-793.

Milić, J., \& Zhou, J. (2018). Residential Satisfaction among Young People in Post-Socialist Countries: The Case of Serbia. Journal of Housing and the Built Environment, 33(4), 715-730.

Mohit, M. A., \& Azim, M. (2012). Assessment of Residential Satisfaction with Public Housing in Hulhumale', Maldives. Procedia: Social and Behavioral Sciences, 50, 756-770. https://doi.org/10.1016/j.sbspro.2012.08.078 
Mohit, M. A., Ibrahim, M., \& Rashid, Y. R. (2010) Assessment of residential satisfaction in newly designed public low-cost housing in Kuala Lumpur, Malaysia. Habitat International, 34(1), 18-27.

Moore, H. P., Carswell, A. T., Worthy, Sh., \& Nielsen, R. (2019). Residential Satisfaction among College Students: Examining High-End Amenity Student Housing. Family and Consumer Sciences Research Journal, 47(3), 260-275.

Morris, E. W., \& Winter, M. (1975). A Theory of Family Housing Adjustment. Journal of Marriage and Family, 37(1), 79-88.

Najib, N.U.M., Yusof, N.A., \& Abidin, N.Z. (2011). Student Residential Satisfaction in Research Universities. Journal of Facilities Management, 9(3), 200-212.

Paris, D. E., \& Kangari, R. (2005). Multifamily Affordable Housing: Residential Satisfaction. Journal of Performance of Constructed Facilities, 19(2), 138-145.

Parkes, A., Kearns, A., \& Atkinson, R. (2002). What Makes People Dissatisfied with their Neighbourhoods? Urban Studies, 39(13), 2413-2438.

Rioux, L., \& Werner, C.M. (2011). Ageing in Place: Predictors of the Residential Satisfaction of Elderly. Social Indicator Research, 54(2), 173-208.

Rojo, Perez F., Fernandez-Mayoralas, G., \& Pozo-Rivera, E. (2001). Residential satisfaction among aging people living in place. Journal of Environmental Psychology, 31(2), 158-169.

van Praag, B.M.S, Frijters, P., \& Ferrer-i-Carbonell, A. (2003). The anatomy of subjective well-being. Journal of Economic Behavior \& Organization, 51(1), 29-49.

Stanisz, A. (2016). Modele regresji logistycznej [Logistic regression models]. StatSoft Polska.

Vera-Toscano, E., \& Ateca-Amestoy, V. (2008). The Relevance of Social Interactions on Housing Satisfaction. Social Indicators Research, 86(2), 257-74.

Waziri, A.G., Yusof, N., \& Rahim, N.M.S.A. (2014). Occupants housing satisfaction: does age really matter? Urban, Planning and Transport Research, 2(1), 341-53.

Weidemann, S., \& Anderson, J. R. (1985). A Conceptual Framework for Residential Satisfaction, [in:] Home Environments, Human Behavior and Environment, eds. I. Altman, C.M. Werner, Boston, MA: Springer US, 153-82. https://doi.org/10.1007/978-1-4899-2266-3_7 (17 July 2019). 